\title{
Defining asthma in epidemiological studies
}

\author{
J. Pekkanen****, N. Pearce**
}

\begin{abstract}
Defining asthma in epidemiological studies. J. Pekkanen, N. Pearce. (C) ERS Journals Ltd 1999.

ABSTRACT: It has been suggested that, in epidemiological studies, asthma should be defined as symptomatic bronchial hyperresponsiveness (BHR). This paper critically examines the validity of this and alternative methods of defining asthma by reviewing population-based studies validating BHR and symptom questionnaires against asthma defined on the basis of a clinical assessment. It is emphasized that a single definition of asthma will not be applicable to all studies.

When the aim of a study is to compare differences in prevalence of asthma between populations, Youden's Index (sensitivity + specificity - 1) is the best single measure of validity. BHR has similar or better specificity, but much worse sensitivity, and therefore a worse Youden's Index, than symptom questionnaires. When the aim is to estimate relative risks, the validity of the definition of asthma depends more on its positive predictive value. Therefore, more specific methods of detecting asthmatics, such as severe symptoms, diagnoses of asthma, or symptomatic BHR may be most useful in cohort and case-control studies. In contrast, conversely, the method of choice for the first phase of prevalence comparisons is standardized written or video symptom questionnaires.

In order to explore reasons for the differences in asthma prevalence, and to estimate possible differential symptom reporting, questionnaires can be supplemented with bronchial hyperresponsiveness and other testing in subsamples of the symptomatic and nonsymptomatic subjects. However, symptoms and bronchial hyperresponsiveness should usually be analysed separately rather than combined due to the poor agreement between bronchial hyperresponsiveness and clinical asthma. Eur Respir J 1999; 14: 951-957.
\end{abstract}

*Unit of Environmental Epidemiology, National Public Health Institute, PO Box 95, 70701 Kuopio, Finland. **Wellington Asthma Research Group, Wellington School of Medicine, PO Box 7343, Wellington, New Zealand

Correspondence: J. Pekkanen, National Public Health Institute, P.O. Box 95 Kuopio, Finland. Fax: 35817201265

Keywords: Asthma, bronchial

hyperreactivity, questionnaires, sensitivity and specificity, validity

Received: June 251998

Accepted after revision May 231999

This work was conducted during the stay of $\mathrm{J}$. Pekkanen in New Zealand with funding from the Academy of Finland and the Foundation for Allergy Research. The Wellington Asthma Research Group is supported by a Programme Grant from the Health Research Council of New Zealand, and by a major grant from the Guardian Trust (Trustee of the David and Cassie Anderson Medical Charitable Trust).

Most epidemiological studies have used symptom questionnaires to distinguish between asthmatics and nonasthmatics because of their advantages in terms of cost, convenience, and the resulting optimization of sample sizes and response rates. Symptom questionnaires have, however, potential problems arising from subjective symptom recognition and recall. In search of more "objective" markers of asthma, it has been suggested that, in epidemiological studies, asthma should be defined based on the presence of asthma symptoms together with bronchial hyperresponsiveness (BHR) [1, 2]. However, the assumption that "objective" measurements, such as BHR, are more valid than a symptom questionnaire is not necessarily true [3] and needs to be tested in validation studies.

Validation of survey instruments is usually done by comparing the results from the instrument to the "gold standard" test. However, asthma has many phenotypes [4] and currently there is no gold standard for defining asthma. Most old and new definitions [2, 5] of asthma highlight variable airflow obstruction and this definition is still followed in clinical practice. The most recent definition emphasizes inflammation [2]. These definitions are, however, more descriptions of the characteristics of asthma and do not allow clear guidelines for separating asthmatics from nonasthmatics. It has also been argued that asthma has always been a clinical diagnosis and that as yet there is insufficient information available regarding the pathogenesis, prognosis and natural history of asthma to justify a major change in the criteria of asthma [6]. Although clinical diagnosis of asthma is difficult, especially among children, agreement between clinicians appears to be fairly good [7]. Thus, although clinical assessment can not be considered to be a true gold standard of asthma, it currently represents the most appropriate standard for use in validating instruments for epidemiological studies.

The validity of an instrument depends not only on its agreement with the gold standard but also on its intended use. In contrast to the clinical situation, epidemiological studies focus on comparisons between populations or groups of population rather than on individuals. Thus, in epidemiological research, the most valid instrument is the one that introduces the least bias to this comparison. The first requirement for obtaining valid results from epidemiological studies is to use the same well-standardized methods in all the populations to be compared. In addition, the choice of the survey instrument depends on the aims of the particular study and the measure of effect that will be used together with issues such as cost, convenience, sample size and response rate.

In this paper, the existing population-based studies comparing the validity of symptom questionnaires and BHR testing to a clinical examination by a physician or a 
previous diagnosis of asthma are reviewed. Before reviewing these studies, the main issues regarding the validation of epidemiological survey instruments are briefly discussed.

\section{Validity}

\section{Measures of validity}

When validating survey instruments against a "gold standard", the results are usually expressed as sensitivity, specificity, and positive and negative predictive value [8]. Sensitivity is the proportion of subjects with "true" asthma (according to the "gold standard") that the survey instrument classifies correctly and specificity is the proportion of subjects without asthma that the survey instrument classifies correctly. The positive predictive value is the proportion of "true" asthmatics among all those who test positive according to the survey instrument. The sensitivity and specificity do not depend on the underlying "true" prevalence of the disease. Conversely, the positive and negative predictive value depend strongly on the underlying prevalence of the disease, and are therefore not generalizable across populations.

As noted above, the most valid method of detecting asthma in epidemiological studies is the one that introduces the least bias to the measure of effect. In prevalence comparisons, the focus is usually on the absolute difference in prevalence between populations. In this case Youden's index provides an appropriate measure of the validity of a particular question or technique [8]. Youden's Index is the sensitivity plus the specificity minus 1.0. When the sensitivity plus the specificity are equal to 1.0 , i.e. the technique used is no better than random, Youden's Index is 0 and the expected observed risk difference between any two populations is 0 .

In studies of risk factors for asthma, the risk difference is sometimes used as the measure of effect, but more commonly the focus is on the relative risk, which is the rate ratio in a cohort study and the odds ratio in a case/control study [9]. It has been argued that, in this situation specificity is often the most important validity measure [10-13]. However, sensitivity is also important and the bias in relative risk is actually dependent on the positive predictive value of the test [14], which in turn depends on the "true" prevalence of asthma, as well as the specificity and sensitivity of the test. Therefore, estimates of positive predictive value cannot be extrapolated between populations unless it can be assumed that the population prevalences are similar.

\section{Hypothetical example}

These issues are illustrated by the following hypothetical example. The example assumes that a researcher has administered questionnaires and done BHR testing in two groups, A and B (table 1). The study can be thought of as either a prevalence comparison between two areas or a cross-sectional analysis of 2,000 subjects, 1,000 of whom are exposed (B) and 1,000 nonexposed (A). The example further assumes that the "true" prevalence of asthma is $5 \%$ in group A and $20 \%$ in group B. Therefore, the true prevalence difference is $15 \%$ and the true prevalence ratio
4.0. As the true prevalence of asthma is, however, not known to the researcher, two different definitions of asthma are used to compare groups A and B: 1) a question on current wheezing; and 2) current wheezing together with BHR. Assuming the sensitivities and specificities of the instruments are as reported for children by JENKINS et al. [15], the question on wheezing clearly overestimates the prevalence of asthma due to its low specificity; however, it gives a better, and more statistically significant, estimate of the true prevalence difference between the populations than does using wheezing combined with BHR (9.9 and $6.2 \%$ respectively compared with the true difference of $15 \%$ ). In contrast, wheezing with BHR gives a slightly better estimate of the true prevalence ratio between the populations than does the question on wheezing alone (1.44 and 1.76 respectively compared with the true prevalence ratio of 4.0) (table 1).

Thus, even if the specificity of an instrument is fairly high, if the prevalence of the disease in the population is low, the positive predictive value of the test is low. Thus, although the bias in the prevalence ratio is mainly dependent on specificity [11], sensitivity also has a role. In fact, the positive predictive values and prevalence ratios obtained using the two instruments are quite similar.

\section{Other considerations}

The above example (table 1) assumes that the survey instruments classify asthmatics similarly in the two populations, i.e. that misclassification is nondifferential. However, this is often not a valid assumption. A person's response to a given question can depend on a wide variety of psychological, social and cultural characteristics, including healthcare practices, and also on the translation of the questionnaire. Furthermore, standardizing the performance of BHR testing is a major problem, especially in international studies [16], and lung function testing requires good cooperation. Comparisons among children are especially difficult, and it has been concluded that BHR results can not be compared between children of different ages and sizes [17]. These factors can, at least

Table 1. - Hypothetical example, comparing two instruments, of surveys done in populations $A$ and $B$, which have "true" prevalences of asthma of $5 \%$ and $20 \%$, respectively

\begin{tabular}{lccc}
\hline & \multicolumn{3}{c}{ Instrument used for estimate } \\
\cline { 2 - 4 } & \multicolumn{3}{c}{$\begin{array}{c}\text { "Wheezing } \\
\text { with BHR" }\end{array}$} \\
\hline $\begin{array}{l}\text { Prev. in Pop A \% } \\
\text { Prev. in Pop B \% }\end{array}$ & 5 & 22.3 & 8.1 \\
$\begin{array}{l}\text { PPV in Pop A \% } \\
\text { PPV in Pop B \% }\end{array}$ & 20 & 32.2 & 14.2 \\
$\begin{array}{l}\text { Prevalence difference } \\
\text { between A and B }\end{array}$ & 15 & 19 & 29 \\
$\begin{array}{l}\text { Chi-squared test } \\
\text { Prevalence ratio } \\
\text { between A and B } \\
(95 \% \text { CI) }\end{array}$ & 4 & 53 & 66 \\
\hline
\end{tabular}

*: sensitivity $85 \%$, specificity $81 \%{ }^{+}$: sensitivity $47 \%$, specificity $94 \%$, as reported for children by JeNkINS et al. [15]. BHR: bronchial hyperresponsiveness; Prev.: prevalence, Pop: population; PPV: posit. 
Table 2. - Population based studies comparing both symptom questionnaires and bronchial hyperresponsiveness test results with asthma defined on the basis of a clinical assessment by a physician

\begin{tabular}{|c|c|c|c|c|c|c|c|c|}
\hline $\begin{array}{l}\text { First author } \\
\text { [Ref.] }\end{array}$ & $\begin{array}{l}\text { Challenge } \\
\text { symptom }\end{array}$ & $\begin{array}{c}\text { Subjects } \\
\mathrm{n}\end{array}$ & $\begin{array}{l}\text { Age } \\
\text { yrs }\end{array}$ & $\begin{array}{c}\text { Sensitivity } \\
\%\end{array}$ & $\begin{array}{c}\text { Specificity } \\
\%\end{array}$ & $\begin{array}{l}\text { Youden's } \\
\text { Index \% }\end{array}$ & $\begin{array}{c}\mathrm{PPV} \\
\%\end{array}$ & $\begin{array}{c}\text { Prevalence of } \\
\text { asthma } \%\end{array}$ \\
\hline \multirow[t]{6}{*}{ JENKINS [15] } & Hypertonic saline & 91 & $28-44$ & 39 & 90 & 29 & 55 & $23^{\S}$ \\
\hline & Symptoms* & & & 80 & 97 & 76 & 89 & 23 \\
\hline & Both & & & 37 & 99 & 36 & 94 & 23 \\
\hline & Hypertonic saline & 168 & $13-14$ & 54 & 89 & 43 & 64 & $25^{\S}$ \\
\hline & Symptoms ${ }^{+}$ & & & 85 & 81 & 66 & 61 & 25 \\
\hline & Both & & & 47 & 94 & 41 & 74 & 25 \\
\hline \multirow[t]{2}{*}{ De Marco [7] } & Symptoms ${ }^{\#}$ & 811 & $20-44$ & 83 & 87 & 70 & NA & NA \\
\hline & Symptoms ${ }^{\#}$ and methacholine & & & 49 & 99 & 47 & NA & NA \\
\hline
\end{tabular}

*: attacks of asthma or wheezing in last 12 months; ${ }^{+}$: wheezing or whistling in last 12 months; ${ }^{*}$ : wheeze, shortness of breath, attack of asthma or medicines for asthma in last 12 months; ${ }^{\S}$ : estimated from published values. PPV: positive predictive value; NA: not available.

partially, be controlled by developing standardized questionnaires [18, 19], guidelines for translating such questionnaires [20] and video questionnaires regarding asthma [21, 22], and by better standardization of BHR testing.

Misclassification is, however, not the only validity issue in epidemiological studies. In particular, participation in an asthma study may well be associated with having asthma, which would introduce selection bias into the study results. This possible bias is best avoided by achieving a high response rate, which is easier with simple questionnaires than in studies involving detailed tests. The use of histamine and methacholine to test hyperresponsiveness among children has also raised ethical concerns in some countries, resulting in very low response rates in some studies [23, 24]. Questionnaire surveys are also easier and cheaper to administer than BHR tests, enabling larger studies to be performed, and thus reducing random error. This is especially important in asthma epidemiology, as sample sizes of $\geq 1,000$ subjects, but preferably of $\geq 3,000$ subjects, have been recommended for asthma prevalence studies [19].

The definition of asthma may itself introduce bias and/or affect the generalizability of study findings [4]. For example, restricting asthma cases to asthmatics with BHR may affect the generalizability of the study findings to asthmatics without BHR. Also, if a factor increases the risk of asthma through mechanisms that do not involve BHR, then the association will not be identified if BHR is used to define the case group. One possibility is to define only those subjects with doctor-diagnosed asthma as asthmatics. This definition preferentially selects asthmatics that have more contact with health services. If the exposure of interest is also related to the use of health services, as in immunization or antibiotic use, the study results will be biased.

Thus, in summary, assuming that the misclassification of asthma is nondifferential: 1) the instrument with the highest Youden's Index provides the most valid estimate of the prevalence difference; and 2) the instrument with the highest positive predictive value provides the most valid estimate of the prevalence ratio. Furthermore, more restrictive definitions of "asthma" (e.g. "a recent hospital admission for asthma") may have a high positive predictive value, but may not be representative of all cases of asthma. As it cannot always be assumed that the misclassification of asthma is nondifferential, it is important to use several methods and to achieve high response rates.

\section{Comparative validity of symptom questionnaires and bronchial hyperresponsiveness testing}

In this section, the available evidence from populationbased studies comparing sensitivity, specificity, Youden's Index, and the positive predictive value of symptom questionnaires and/or BHR testing against a clinical examination by a physician or a self-report of doctor-diagnosed asthma are reviewed. A Medline search from 1980 onwards was conducted for English language publications of population-based studies containing the keywords "sensitivity and specificity" together with "asthma", "bronchial hyperreactivity" or "bronchial provocation test". In cases

Table 3. - Population-based studies comparing either bronchial hyperresponsiveness test results or symptom questionnaires with asthma defined on the basis of a clinical assessment by a physician

\begin{tabular}{|c|c|c|c|c|c|c|c|c|}
\hline $\begin{array}{l}\text { First author } \\
\text { [Ref.] }\end{array}$ & $\begin{array}{l}\text { Challenge } \\
\text { symptom }\end{array}$ & $\begin{array}{c}\text { Subjects } \\
n\end{array}$ & $\begin{array}{l}\text { Age } \\
\text { yrs }\end{array}$ & $\begin{array}{c}\text { Sensitivity } \\
\%\end{array}$ & $\begin{array}{c}\text { Specificity } \\
\%\end{array}$ & $\begin{array}{l}\text { Younden's } \\
\text { Index \% }\end{array}$ & $\begin{array}{c}\text { PPV } \\
\%\end{array}$ & $\begin{array}{l}\text { Prevalence } \\
\text { of asthma \% }\end{array}$ \\
\hline SEARS $[25]^{*}$ & Methacholine & 791 & 9 & 50 & 84 & 34 & 53 & 25 \\
\hline Cerveri $[32]^{*},+$ & Symptoms $\#$ & 115 & $15-65$ & 56 & 97 & 53 & 45 & 3 \\
\hline RIEDLER [33] & Hypertonic saline & 174 & $13-15$ & 51 & 92 & 43 & NA & $\mathrm{NA}$ \\
\hline & Exercise test & 174 & $13-15$ & 57 & 90 & 47 & NA & NA \\
\hline REMES [29]* & Symptoms ${ }^{\text {s }}$ & 247 & $7-12$ & 88 & 97 & 85 & 53 & 4 \\
\hline & Asthma & 247 & $7-12$ & 82 & 99 & 81 & 76 & 4 \\
\hline STEEN-JOHNSEN $[34]^{*,+}$ & Symptoms & 96 & $7-13$ & 63 & 99 & 62 & 92 & 13 \\
\hline
\end{tabular}

*: figures calculated from published values; ${ }^{+}$: figures differ from those in the original publication, which does not adjust for the sampling method; ": "Attacks of breathlessness with wheeze" ever; ${ }^{\S}$ : Doctor diagnosis of asthma ever or "attacks of wheezing" or "breathlessness" in the last 12 months; ": Doctor diagnosis of asthma ever; + : "ever asthma" or asthma symptoms after exposure to extrinsic factors. PPV: positive predictive value; NA: not available. 
Table 4. - Population-based studies comparing bronchial hyperresponsiveness test results with self-report of physiciandiagnosed asthma

\begin{tabular}{|c|c|c|c|c|c|c|c|c|}
\hline $\begin{array}{l}\text { First author } \\
\text { [Ref.] }\end{array}$ & Challenge & $\begin{array}{c}\text { Subjects } \\
\mathrm{n}\end{array}$ & $\begin{array}{l}\text { Age } \\
\text { yrs }\end{array}$ & $\begin{array}{c}\text { Sensitivity } \\
\%\end{array}$ & $\begin{array}{c}\text { Specificity } \\
\%\end{array}$ & $\begin{array}{l}\text { Youden's } \\
\text { Index \% }\end{array}$ & $\begin{array}{c}\text { PPV } \\
\%\end{array}$ & $\begin{array}{c}\text { Prevalence } \\
\text { of diagnosed } \\
\text { asthma } \%\end{array}$ \\
\hline SALOME $[30]^{*}$ & Histamine & 2363 & $8-11$ & 53 & 87 & 40 & 38 & 13 \\
\hline PATTEMORE [35] & Histamine & 2053 & $7-10$ & 52 & 90 & 42 & 47 & 14 \\
\hline \multirow[t]{4}{*}{ BACKER $[36]^{+}$} & Histamine & 495 & $7-16$ & & & & & \\
\hline & PC6 & & & 100 & 74 & 74 & 19 & 6 \\
\hline & $\mathrm{PC} 12$ & & & 75 & 93 & 68 & 40 & 6 \\
\hline & PC20 & & & 57 & 98 & 55 & 59 & 6 \\
\hline \multirow[t]{4}{*}{ FORASTIERE $[37]^{+}$} & Methacholine & 1777 & $7-11$ & & & & & \\
\hline & $64 \mathrm{mg} \cdot \mathrm{mL}^{-1}$ & & & 72 & 52 & 24 & NA & 7 \\
\hline & $4 \mathrm{mg} \cdot \mathrm{mL}^{-1}$ & & & 43 & 87 & 30 & 19 & 7 \\
\hline & $1 \mathrm{mg} \cdot \mathrm{mL}^{-1}$ & & & 22 & 96 & 18 & NA & 7 \\
\hline FRISCHER [38] & Distilled water & 446 & $7-10$ & 36 & 92 & 28 & 11 & 3 \\
\hline NicOLaI [23] & Cold air & 5697 & $9-11$ & 31 & 88 & 19 & 18 & 8 \\
\hline \multirow[t]{2}{*}{ НАВY [27] } & Histamine & 94 & $7-12$ & 23 & 94 & 17 & 10 & 32 \\
\hline & Exercise & 94 & $7-12$ & 27 & 95 & 22 & 12 & 32 \\
\hline \multirow[t]{5}{*}{ BURR [28] } & Exercise & & & & & & & \\
\hline & New-Zealand & 868 & 12 & 35 & 92 & 27 & 48 & 17 \\
\hline & Wales & 960 & 12 & 40 & 97 & 37 & 61 & 12 \\
\hline & South Africa & 1174 & 12 & 23 & 98 & 21 & 63 & 12 \\
\hline & Sweden & 1250 & 12 & 12 & 98 & 10 & 22 & 4 \\
\hline JoNES [39] & Exercise & 949 & $4-11$ & 39 & 93 & 32 & 35 & 9 \\
\hline Ponsonby [40] & Exercise & 191 & 7 & 45 & 78 & 22 & $45^{*}$ & 29 \\
\hline WoOLCOCK $[31]^{*}$ & Histamine & 916 & $18-88$ & 47 & 92 & 39 & 38 & 9 \\
\hline COCKCROFT [26]* & Histamine & 484 & $20-29$ & 52 & 91 & 43 & 28 & 6 \\
\hline
\end{tabular}

*: figures calculated from published values; ${ }^{+}$: self-report of diagnosis of asthma or, in a few subjects, symptoms; ${ }^{\#}$ : "Asthma ever". PPV: positive predictive value; PC6, PC12 and PC20: provocative concentration of histamine causing, respectively, a $6 \%, 12 \%$ and $20 \%$ fall in forced expiratory volume in one second; NA: not available.

of several reports from one fieldwork, only one report was selected. From the lists of references of the selected articles and other literature, several additional articles, of which seven are included in tables 2-4 [25-31] were found.

Several population-based studies [7, 32, 34, 41-43] did not adjust their analyses for the sampling method used; thus, the reported sensitivities and specificities may not apply to the original source population [44]. Therefore, those studies in which results adjusted for sampling could not be calculated from the published figures were excluded. However, given the small number of studies comparing both symptoms and BHR with clinical diagnoses of asthma, the study of DE MARCO et al. [7] was included, although the analyses were not adjusted for the sampling method used.

The cut-off point chosen to define BHR strongly affects the sensitivity and specificity of the BHR test. Except for two studies [36, 37], the results shown in the tables for studies using methacholine or histamine challenge are for BHR defined as a $20 \%$ fall in forced expiratory volume in one second (FEV1) at the maximum dose or concentration used. This maximum dose was, however, often different in different studies. In contrast, several of the studies using other challenges $[23,33,38,40]$ attempted to find the optimal definition of BHR in terms of sensitivity and specificity, and this definition is reported in the tables.

\section{Comparison with clinical assessment by a physician}

There were only two population-based studies that compared, in the same population, results from BHR and symptom questionnaires to a careful clinical assessment by a physician. JenKINS et al. [15], in population samples of adults aged 28-44 yrs and of children aged 13-14 yrs, compared results from a symptom questionnaire and from a hypertonic saline challenge with diagnoses of current asthma based on a blinded history taken by a trained physician (table 2). Self-reported symptoms had a higher Youden's Index than did BHR both among children and young adults, mainly due to the better sensitivity of symptom questionnaires. Combining symptoms with BHR increased specificity, especially among children, but caused a strong decline in sensitivity, thereby decreasing Youden's Index to a lower level than that found using either symptoms or BHR alone (table 2). The differences in positive predictive value were not large, except for the lower positive predictive value of BHR among adults. The generally high positive predictive values in this study are partly explained by the high prevalence of asthma in these populations.

In a population-based sample of young adults [7], three experienced clinicians made independent assessments regarding the presence of asthma on the basis of answers to a detailed standardized interview, and results from lung function, methacholine challenge, immunoglobulin $\mathrm{E}$, and skin prick tests. Agreement in the assessments between clinicians was fairly good (Cohen $\kappa 0.71)$. The results (table 2) are consistent with those of JENKINs et al. [15]. However, the reported results are not adjusted for the oversampling of those subjects with respiratory symptoms.

BURNEY et al. [45] studied 20 selected adult asthma cases and 20 controls in four centres in Europe both with 
a histamine challenge and a symptom questionnaire. The selection of the asthma cases and controls was, however, not population-based and varied between centres. In this study, the question on "asthma" during the last year had a sensitivity of $55 \%$ and a specificity of $96 \%$, and BHR with symptoms had a sensitivity of $44 \%$ and a specificity of $98 \%$.

Several population-based studies have validated either symptoms or BHR against physician's assessment (table 3 ), mostly in children. The results regarding sensitivity and specificity of BHR agree closely with those reported by JENKINS et al. [15]. The studies show that symptom questionnaires can also be worded to be very specific among children, which in turn tends to lower their sensitivity.

Comparison of bronchial hyperresponsiveness with self-reported asthma diagnosis

Many other population-based studies have compared BHR tests with a self-report of doctor-diagnosed asthma ever in life (table 4). These comparisons are less reliable as they are affected by possible underdiagnosis and underreporting of asthma. However, in general, they agree with the results of JENKINS et al. [15] with specificities of approximately $\geq 90 \%$, sensitivities of $20-50 \%$ and a Youden's index of approximately $\leq 40 \%$.

All but two of these studies have been performed among children. The results among adults are supported by two other population-based studies reporting a sensitivity of $32 \%$ and a specificity of $94 \%$ for methacholine challenge in detecting those middle-aged and elderly men reporting that they had ever had "asthma" [46] and a sensitivity of $56 \%$ and a specificity of $77 \%$ for histamine challenge in detecting those men aged 14-64 yrs reporting asthmatic attacks [47]. A study among 1,392 selected workers reported a sensitivity of $61 \%$ and a specificity of $85 \%$ for methacholine challenge in detecting those men with physician-diagnosed asthma [48].

BACKER et al. [36] used several different cut-off points of BHR. Using a histamine concentration of $2.4 \mathrm{mg} \cdot \mathrm{mL}^{-1}$ and a $20 \%$ fall in FEV1 (provocative concentration of histamine causing a $20 \%$ fall in FEV1 (PC20)) to define asthma, the definition was again highly specific for asthma, but was of low sensitivity (57\%). Making the definition of BHR less severe increased sensitivity such that the provocative concentration of histamine causing a $6 \%$ fall in FEV1 (PC6) had a sensitivity of $100 \%$, but the specificity decreased to $74 \%$, yielding, however, the best value of Youden's Index (0.74). The positive predictive value was best with the more severe definition (PC20). FORASTIERE et al. [39] performed similar analyses, but varied the concentration of methacholine required to produce a $20 \%$ fall in FEV1 (table 4 ).

It might be hypothesized that repeated measurements of BHR would give a better classification of subjects into asthmatics and nonasthmatics. BuRrows et al. [49] studied the same 573 children at ages 9, 11, 13, and 15 yrs. Using airway responsiveness at at least one of the four examinations as evidence of BHR, they produced a sensitivity of $65 \%$, specificity of $71 \%$, and Youden's Index of $36 \%$ for frequent wheezing in the past 2 yrs at the age of 15 yrs. Conversely, using at least moderate responsiveness at all four examinations as evidence of BHR, the sensitivity was $17 \%$, the specificity $98 \%$ and Youden's Index 15\%. Thus, again, a more severe definition gave a higher specificity but a lower Youden's Index. However, neither definition of BHR provided good agreement with asthma symptoms.

\section{Conclusions}

Findings from the population-based studies reviewed here show a poor sensitivity of BHR in detecting asthmatics in contrast with conclusions from clinical studies which have found the sensitivity of BHR to be $>90 \%$ [50]. This is partly due to the case mix in the clinical studies [44], as BHR does not fare so well in a general population survey that includes many mild or borderline asthmatics, and in which many of the nonasthmatics have atopy, a family history of asthma or respiratory diagnoses other than asthma [51]. In addition, clinical studies as well as several population-based studies [7, 32, 34, 41-43] have not adjusted for the sampling method used in their analyses and there-fore the reported sensitivities and specificities may not be representative of the original source population [44].

The continuous nature of BHR in the population means that the sensitivity of BHR in detecting asthmatics can be increased by defining BHR as very mild hyperresponsiveness. However, this in turn decreases the specificity, and even when the cut-off point of BHR has been examined in this way [23, 33, 36-38, 40], the agreement between BHR and asthma remains poor. The same conclusion was drawn from a recent Bayesian analysis, which allows for the estimation of test properties when no gold standard test is available [52].

Given the current problems in defining what actually constitutes asthma, the focus of epidemiological research should be less on trying to estimate the "actual prevalence of asthma" [53] in a population, and more on comparing the prevalence of asthma between population groups using standardized methods. When the aim is to study differences in asthma prevalence, the available evidence from population-based studies indicates that questions on symptoms have a higher Youden's Index, and therefore greater validity than BHR alone or BHR in combination with symptoms.

In epidemiological studies of the causes of asthma, the situation is less clear. In these studies, the relative risk is often the effect measure of interest and the validity of a survey instrument is usually more dependent on its positive predictive value. More specific definitions of "asthma" may therefore have greater validity in this context. A more specific definition can be obtained by defining asthma as severe symptoms or a combination of symptoms [22], doctor-diagnosed asthma, positive results on BHR testing or combining BHR with symptoms $[1,2]$. However, less information is available on the relative validity of these approaches.

Whatever method is used, it should be validated, preferably in a subsample of the populations studied. This allows the estimation of the degree of bias in a study and even correction for it [14]. When performing a prevalence survey, a good means of combining the best qualities of the symptom questionnaires and BHR testing is to first 
perform a large questionnaire survey and then do more intensive examinations on a subsample $[18,19]$. However, it should be stressed that both symptomatic and nonsymptomatic subjects need to be examined. This has unfortunately not always been carried out $[53,54]$, which makes it impossible to estimate the extent of misclassification in the questionnaire survey.

In conclusion, no single method of detecting asthmatics will suit all epidemiological studies. In cohort and casecontrol studies, specific methods for detecting asthmatics, such as severe symptoms, diagnoses of asthma or symptomatic bronchial hyperresponsiveness, are most useful. In contrast. the method of choice for the first phase of prevalence comparisons is a standardized written or video symptoms questionnaire. To explore reasons for the differences in asthma prevalence, and to estimate possible differential symptom reporting, questionnaires can be supplemented with bronchial hyperresponsiveness and other testing in subsamples of the symptomatic and nonsymptomatic subjects. However, symptoms and bronchial hyperresponsiveness should usually be analysed separately rather than combined due to the poor agreement between bronchial hyperresponsiveness and clinical asthma.

\section{References}

1. Toelle BG, Peat JX, Salome CM, et al. Toward a definition of asthma for epidemiology. Am Rev Respir Dis 1992; 146: 633-637.

2. Global Initiative for Asthma. Global Strategy for Asthma Management and Prevention. NHLBI/WHO Workshop Report. National Institute of Health. Publication no. 953659. 1995.

3. Pearce NS. Sanjose P, Boffetta P, et al. Limitations of biomarkers of exposure in cancer epidemiology. Epidemiol 1995; 6: 190-194.

4. Kauffmann F, Dizier M-H, Pin I, et al. Epidemiological study of the genetics and environment of asthma, bronchial hyperresponsiveness and atopy. Am J Respir Crit Care Med 1997; 156: S123-S129.

5. World Health Organization (WHO). Epidemiology of chronic non-specific respiratory diseases. Bull WHO 1975; 52: 251-259.

6. Britton J, Lewis S. Objective measures and the diagnosis of asthma. Br Med J 1998; 17: 227-228.

7. De Marco R, Cerveri I, Bugiani M, Ferrari M, Verlato G. An undetected burden of asthina in Italy: the relationship between clinical and epidemiological diagnosis of asthma. Eur Respir J 1998; 11: 599-605.

8. Pearce N, Beasley R, Burgess C, Crane J. Asthma epidemiology: principles and methods. New York, Oxford University Press, 1998.

9. Pearce NE. What does the odds ratio estimate in a casecontrol study? Int J Epidemiol 1993; 22: 1189-1192.

10. Green MS. Use of predictive value to adjust relative risk estimates biased by misclassification of outcome status. Am J Epidemiol 1983; 117: 98-105.

11. Copeland KT, Checkoway H, McMichael AJ, et al. Bias due to misclassification in the estimation of relative risk. Am J Epidemiol 1977; 105: 488-495.

12. Poole C. Exception to the rule about nondifferential misclassification (Abstract). Am J Epidemiol 1985; 122: 508.

13. Toren K, Brisman J, Järvholm B. Asthma and asthma-like symptoms in adults assessed by questionnaires. Chest 1993; 104: 600-608.

14. Brenner H, Gefeller O. Use of positive predictive value to correct for disease misclassification in epidemiological studies. Am J Epidemiol 1993; 138: 1007-1015.

15. Jenkins MA, Clarke JR, Carlin JB, et al. Validation of questionnaire and bronchial hyperresponsiveness against respiratory physician dssessment in the diagnosis of asthma. Int J Epidemiol 1996; 25: 609-616.

16. Chinn S, Arossa WA, Jarvis DL, Luczynska CM, Burney PG. Variation in nebulizer aerosol output and weight output from the Mefar dosimeter: implications for multicentre studies. Eur Respir J 1997; 10: 452-456.

17. Le Souef PN. Can measurements of airway responsiveness be standardized in children? Eur Respir J 1993; 6: 1085-1087.

18. Burney PGJ, Luczynska C, Chinn S, Jarvis D. The European Community Respiratory Health Survey. Eur Respir J 1994; 7: 954-960.

19. Asher I, Keil U, Anderson HR, et al. International Study of Asthma and Allergies in Childhood (ISAAC): rationale and methods. Eur Respir J 1995; 8: 483-491.

20. Weiland S. Guidelines for the translation of questionnaires. ISAAC Newsletter. 1994; ISAAC Document 041: March: p. 2.

21. Shaw RA, Crane J, Pearce NE, et al. Validation of a video questionnaire for assessing asthma prevalence. Clin Exper Allergy 1992b; 22: 562-569.

22. Lai CK, Chan JK, Chan A, et al. Comparison of the ISAAC video questionnaire (AVQ3.0) with the ISAAC written questionnaire for estimating asthma associated with bronchial hyperreactivity. Clin Exp Allergy 1997; 27 : 540-545.

23. Nicolai T, Von Mutius E, Reitmeir P, Wjst M. Reactivity to cold-air hyperventilation in normal and asthmatic children in a survey of 5,697 schoolchildren in Southern Bavaria. Am Rev Respir Dis 1993; 147: 565-572.

24. Frischer $\mathrm{T}$, Kühr $\mathrm{HR}$, Meinert $\mathrm{R}$, et al. Prävalenz Allergischer Manifestationen im Schulkindalter in Südbaden. Münch Med Wschr 1991; 133: 671-674.

25. Sears MR, Jones DT, Holdaway MD, et al. Prevalence of bronchial reactivity to inhaled methacholine in New Zealand children. Thorax 1986; 41: 283-289.

26. Cockcroft WD, Murdock KY, Berscheid BA, Gore BP. Sensititivy and specificity of histamine $\mathrm{PC} 20$ determination in a random sample of young college students. $J$ Allergy Clin Immunol 1992; 89: 23-30.

27. Haby MM, Anderson SD, Peat JK, Mellis CM, Toelle BG, Woolcock AJ. An exercise protocol for epidemiological studies of asthma in children: comparison with histamine challenge. Eur Respir J 1994; 7: 43-49.

28. Burr ML, Limb ES, Andrae S, et al. Childhood asthma in four countries: a comparative survey. Int J Epidemiol 1994; 23: 341-347.

29. Remes ST, Korppi M, Remes K, Pekkanen J. Prevalence of asthma at school age: a clinical population-based study in eastern Finland. Acta Paediatr 1996; 85: 59-63.

30. Salome CM, Peat JK, Britton WJ, Woolcock AJ. Bronchial hyperresponsiveness in two populations of Australian schoolchildren. I. Relation to respiratory symptoms and diagnosed asthma. Clin Allergy 1987; 17: 271-281.

31. Woolcock AJ, Peat JK, Salome CM, et al. Prevalence of bronchial hyperresponsiveness and asthma in a rural adult population. Thorax 1987; 42: 361-368.

32. Cerveri I, Bruschi C, Ricciardi M, Zoecchi L, Zoia MC, Rampulla C. Epidemiological diagnosis of asthma: 
Methodological considerations of prevalence evaluation. Eur J Epidemiol 1987; 3: 202-205.

33. Riedler J, Reade T, Dalton M, et al. Hypertonic saline challenge in an epidemiologic survey of asthma in children. Am J Respir Crit Care Med 1994; 150: 1632-1639.

34. Steen-Johnsen J, Bolle R, Holt J, Benan K, Magnus P. Impact of pollution and place of residence on atopic diseases among schoolchildren in Telemark County, Norway. Pediatric Allergy Immunol 1995; 6: 192-199.

35. Pattermore PK, Innes Asher M, Harrison A-C, Mitchell EA, Rea HH, Stewart AW. The interrelationship among bronchial hyperresponsiveness, the diagnoses of asthma, and asthma symptoms. Am Rev Respir Dis 1990; 142: 549-554.

36. Backer V, Groth S, Dirksen A, et al. Sensitivity and specificity of the histamine challenge test for the diagnosis of asthma in an unselected sample of children and adolescents. Eur Respir J 1991; 4: 1093-1100.

37. Forastiere F, Pistelli R, Michelozzi P, et al. Indices of nonspecific bronchial responsiveness in a pediatric population. Chest 1991; 100: 927-934.

38. Frischer T, Studnicka M, Neumann M, Götz M. Determinants of airway response to challenge with distilled water in a population sample of children aged 7 to 10 years old. Chest 1992; 102: 764-770.

39. Jones A. Asymptomatic bronchial hyperreactivity and the development of asthma and other respiratory tract illnesses in children. Thorax 1994; 49: 757-761.

40. Ponsonby A-L, Couper D, Dwyer T, Carmichael A, Wood-Baker R. Exercise-induced bronchial hyperresponsiveness and parental ISAAC questionnaire responses. Eur Respir J 1996; 9: 1356-1362.

41. Edfors-Lubs ML. Allergy in 7000 twin pairs. Acta Allergol 1971; 26: 249-285.

42. Weiss ST, Tager LB, Weiss JW, Munoz A, Speizer FE, Ingran RH. Airway responsiveness in a population sample of adults and children. Am Rev Respir Dis 1984; 129: 898-920.

43. Sierstedt HC, Hansen HS, Hansen N-CG, Hyldebrandt N, Mostgaard G, Oxhøj H. Evaluation of peak expiratory flow variability in an adolescent population sample. $A m J$ Respir Crit Care Med 1994; 149: 598-603.
44. Begg CB. Biases in the assessment of diagnostic tests. Stat Med 1987; 6: 411-423.

45. Burney PGJ, Laitinen L-A, Perdrizet S, et al. Validity and repeatability of the IUALTD (1984) bronchial symptoms questionnaire: and international comparison. Eur Respir $J$ 1989; 2: 940-945.

46. O'Connor GT, Sparrow D, Weiss ST. Normal range of methacholine responsiveness in relation to prechallenge pulmonary function. Chest 1994; 105: 661-666.

47. Rijcken B, Schouten JP, Weiss ST, Speizer FE, van der Lende R. The relationship of nonspecific bronchial responsiveness to respiratory symptoms in a random population sample. Am Rev Respir Dis 1987; 136: 62-68.

48. Enarson DA, Sverre V, Schulzer M, Dybuncio A, ChanYeung M. Asthma, asthmalike symptoms, chronic bronchitis, and the degree of bronchial hyperresponsiveness in epidemiological surveys. Am Rev Respir Dis 1987; 136: 613-617.

49. Burrows B, Sears MR, Flanner EM, Herbison GP, Holdaway MD, Silva PA. Relation of the course of bronchial responsiveness from age 9 to age 15 to allergy. Am J Respir Crit Care Med 1995; 152: 1302-1308.

50. Boushey HA, Holtzman MJ, Sheller JR, Nadel JA. Bronchial hyperreactivity. Am Rev Respir Dis 1980; 121: 389-413.

51. Britton J, Tattersfield AE. Does measurement of bronchial hyperreactivity help in clinical diagnosis of asthma? Eur $J$ Respir Dis 1986; 68: 233-238.

52. Demissie K, White N, Joseph L, Ernst P. Bayesian estimation of asthma prevalence, and comparison of exercise and questionnaire diagnostics in the absence of a gold standard. Ann Epidemiol 1998; 8: 201-208.

53. Kim YY, Cho SH, Kim WK, Parks JK, Song SH, Kim YK, et al. Prevalence of childhood asthma based on questionnaires and methacholine bronchial provocation test in Korea. Clin Exp Allergy 1997; 27: 761-768.

54. Norrman E, Rosenhall L, Nyström L, Bergström E, Stjernberg N. High prevalence of asthma and related symptoms in Northern Sweden. Eur Respir J 1993; 6: 834-839. 